\title{
Challenge and Prospect of Ethiopian Tourism Policy
}

\author{
Yimer Ali \\ Lecturer, Department of Department of Civic and Ethic studies \\ College of social science, Wolaita Sodo university, Ethiopia, po.box:138
}

\begin{abstract}
In Ethiopia nature, culture and history merge to form a timeless appeal. The countries impressive tourism potential is truly a land of contrast and extremes, a land of remote and wild place, and of spectacular alpine terrain-including the semien mountain national park with its high 4620 meters peak at Ras Dashen one of UNESCO registered heritage site; and at the other end of spectrum, the Denakil depression 121 meters below sea level is among the lowest places on earth. However from these abundant resources the country has not benefited yet. Therefore questions about how tourism policies contribute to national development? What is wrong with the existing system? Why should the present policy be discarded? How did it become successful? These and similar other questions will have to be addressed first before proposing what measures should be taken to ameliorate the situation. For this reason, a brief account of the country's tourism needs to be provided
\end{abstract}

Keywords: tourism policy, attractions, challenge, prospect

\section{Introduction}

As tourism continues to become more competitive, governments having to adopt a more entrepreneurial role in attracting not only tourists but also investors to their region. For instance in Ethiopia with growing tourism the government expanded infrastructures like road, new air port destinations, vehicles and hotels (private and governmental) etc. The questions raised surrounding tourism as a regional development tool deal with whether or not there can be real regional economic dispersion of the benefits of tourism. Tourism development projects, which do not build strong linkages to the surrounding community, will have little impact on the citizens who live nearby. Questions need to be asked about the most appropriate forms of tourism development growth poles so that the trickle-down effect can be maximized. While tourism may help to modernize a region, it may also cause the region to become dependent on external organizations.

It is argued that community-based, grassroots tourism is a more sustainable form of development than conventional mass tourism as it allows communities to break away from the hegemonic grasp of tour operators and the oligopoly of local élites. It is argued that there needs to be a decentralization of tourism down to the community level. When I take this one to Ethiopian context, it is necessary for enhancement of tourism as well as generating additional funding, which circulates in the local community/population, self-esteem is enhanced for the community as control over the development process is maintained locally. Developing community-based tourism can be especially difficult in developing countries in term of such issues as access to information, lack of awareness and lack of access to finances and policy frame work. The peripheral nature of many communities interested in community-based tourism development raises questions as to how they will attract visitors.

Much of the research on tourism employment is based in a western-centric, developed country perspective where tourism positions are often considered as seasonal and low paying. There for developing countries like Ethiopia has not earn sufficient income from tourism sector. In a developing country context, however, employment opportunities are more limited but have higher relative rates of payment than in other economic sectors. Even if positions are seasonal they are highly sought after. When possible policy set properly, tourism employment can create opportunities for the local population to increase their income and improve their standard of living. It can also provide new opportunities for youth and women. A model based on service-centred tourism employment was presented as much of the work in tourism employment research has borrowed models from manufacturing and related models of production. Here, the gap between the concepts of socioeconomic development and socio cultural impacts of tourism development was explored. Many of the predominant theories of development have emerged from western schools of thought without much consideration being given to more traditional methods of development. Classifications of the major indices for social and economic development including income, trade, resource and quality of life are based within a western or modernisation framework. Within this framework, both economic development and the modernisation of living standards are expected to go hand in hand. However, indigenous lifestyles and the customs of some host communities, for example, are valuable commodities and movement to modernise these societies is criticised by the tourism industry. As a solution developing countries like Ethiopia should have to prepare tourism policy in considering this and other threats. By examining the complex nature of the relationship between the positive and negative impacts of tourism the writers argued that the applicability of measuring socioeconomic development based in a western framework to understand tourism development needs to be questioned(like Africa). 
To determine the policy impact on the host's society, it analyses differently in different place. After tracing the evolution of sustainable development it was then argued that sustainable tourism development has failed as a result of environmental managerialism inherent in sustainable development principles. Attempts at imposing a universal blueprint for tourism development, or the using of a set of 'meta-principles' which are founded on mainstream planning and designation processes, are inappropriate within the complex developmental contexts and the needs of tourism destinations particularly in developing countries. A more relevant interpretation of tourism and sustainability in terms of what it is and how it can be achieved is necessary. It was argued that concepts be utilized in non-western settings? Again, is there a successor to sustainable tourism development?

While tourism has potential to contribute to the economic and social development of a destination, there are characteristics of the industry, which limit its potential as a development tool. The emerging global power structures of the tourism industry can take control out of the hands of the destination leaving only the local élites and multinational corporations to benefit. It was also argued that tourists themselves are more generally interested in themselves and their needs as opposed to altering their form of consumption to maximize the benefits of tourism for the destination. Though the Ethiopian government drafted the tourism development policy in order to maximize benefit and accelerate Ethiopian tourism industry from its low stage.

\section{Objectives}

As Ethiopia is blessed with abundant natural tourist attractions, the primary objective of the study was to clearly asses the challenge and prospect of Ethiopian tourism policy.

\section{Literature review}

\section{Historical Development of Tourism in Ethiopia}

According to the ministry of tourism and culture, tourism as one of the economic sector came into being in Ethiopia very recently. It was around 1960, that the potential of tourism drew the attention of the imperial government authorities. The first tourism office was established in 1962. However, a set back in international tourism demand had been seen during the military regime

From 1974 for two decades the industry was suffering from various adverse effects such as prolonged civil war, recurrent drought and restrictions on entry and free movement of tourists (World Bank, 2006). Though the sector is still at its infant stage, it has been keep growing since 2001. The total receipt from the industry in 2008 was around 204.9 million USD. As of 2008, international tourists arrivals was reached to $383,399$. However, the sector's share to GDP is remains very small $(0.77 \%$ in 2008$)$.

Successive Ethiopian governments have promoted tourism during their tenures. The monarchy that mediated politics, economics, culture, environment and technology for most of the $20^{\text {th }}$ century initiated the promotion, marketing and development of tourism as an integral part of the overall dynamics of national development. Ethiopia's existence as an independent country for thousands of years and the diversity of its ecology and culture were images that captivated foreigners for a long time. The promotional logo of 'Thirteen months of Sunshine" was interjected by an imaginary of a proud and cultured people professing the two major universal religions of the world-Christianity and Islam and an ethnic religion of Felasha Jewry. The magnificent material iconographies of Ethiopian culture were relayed to the visitor through the timeless architectural wonders of Axum's stele, Lalibela's rockhewn churches, Gondar's Castles, Harar's medieval walled city and archeological sites that traced the origin of homo-sapiens to the Rift valley where the skeletal remains of Dinkinesh (Lucy) and Selam were discovered.

Marketing and promoting have been, however, the weakest areas of tourism development. The negative imageries that framed the country following the famines and political strife of the $1970-1990$ period defined tourist perceptions of the country to a considerable extent. Some tour promoters have even gone further by proposing that the tourist gaze in Ethiopia was a moralistic experience. Such perspective was suggested by "Lonely Planet" in the following introduction of the tourist experience in Ethiopia as "testing, inspiring and heartbreaking-a journey you will never forget. You do not explore Ethiopia for a relaxing getaway, you venture here to be moved and moved you should be" (http://www.lonelyplanet.com/Ethiopia) (Tadesse KidaneMariam,2015)

Ethiopia's possession of varied attractions regarded as an opportunity for the tourism sector policy . However at present the Ministry identified the following major challenges also confronting the sector:

$>$ Heritages of the country has not been adequately protected, developed and used as a tourist attraction.

$>$ There is a serious shortage in number and type of tourist facilities. Moreover, the quality of service is poor and unsatisfactory to tourists.

$>$ Performing arts, entertainment services and other local creative products, which could have helped to lengthen the stay of visitors, are not offered in sufficient variety. 
$>$ There is a shortage of trained manpower that is crucial to the development of the sector.

$>$ Weak mutual support and coordination among tourism stakeholders.

$>$ Ethiopia's image on the international scene is widely associated with draught, famine and war.

$>$ The horn of Africa is regarded as a region of instability and terrorism.

\section{The roles of state level institutions and policy measures}

Currently there are eleven regional cultural and tourism bureaus in Ethiopia, which are accountable for the Ministry of Culture and Tourism (MCT). Apart from the Ministry, these regional bureaus have also their own five year strategic plan. However, their independent initiatives lacks coordination with other stakeholders including the Ministry.

Regarding policy issues since 2005, the government's initiation to promote tourism has been increasing. Starting from public statements issued by the Prime Minister supporting tourism there are indications that the government is opening a committed dialogue on tourism

"My government believes that an increased focus on tourism can play more significant role in the war on poverty, both in Ethiopia and across Africa as a whole” PM Meles (2005) Adapted from World Bank (2006)

The first tourism development policy of the country was enacted in August, 2010. Lessening the aforementioned challenges was the origin for this policy initiative.

In line with the tourism development policy, MCT introduce a strategic plan for the sector every five year. However, the strategic plan (2010-2015) designed more ambitiously so as to fit the objectives of GTP in the tourism arena.

- Some of the following figures make the plan more ambitious;

I. To increase a tourism receipt from the current 250 million USD to 3 billion USD.

II. To create a tourism jobs for 3.5 million citizens.

III. To achieve a tourism promotion activities by $100 \%$

IV. To increase tourist's service satisfaction from $51 \%$ to $90 \%$

V. To improve the capacity of implementing international agreements and conventions from $25 \%$ to $90 \%$

The undone roles of stakeholders in implementation

Most of the stakeholders such as the federal government, regional government, private sectors and local communities are not fully playing their roles in implementing the policy.(Temesgen K.,2014)

Among these undone tasks, the followings are the major one under different stakeholders;

A. Federal and regional governments

$>\quad$ To expand and improve the development of infrastructural facilities

$>$ To capably coordinate and lead vigorous marketing and promotion activities

$>$ To ensure the psychological and physical well-being of visitors

B. Private sectors

$>$ Protection of heritages in collaboration with local communities

$>$ To participate in the provision of quality tourism services in types and capacities required

$>$ To involve in the expansion of infrastructure needed in the localities of major destinations

$>$ To participate in the protection of attractions

$>$ To participate in associations for mutual support

C. Local communities at tourist destinations

$>$ To provide appropriate care to guests visiting the local attractions

$>$ To protect cultural and social values from negative influence of tourism

$>$ Conserving cultural resources with a sense of ownership

The ambitious Growth and transformation plan II (GTPII) which has been implemented now expected to fill the gaps. To this end Ministry of Culture and Tourism of Ethiopia has targeted to earn six billion USD revenue from the tourism sector in its second Growth and Transformation Plan II.The contribution of the tourism sector to the country's GTP so far is about 1.2 percent and that it is now planned to raise its contribution to 5 percent.Indeed the influx of foreign visitors to Ethiopia has shown an average growth of 10 percent in the past seven years, the average tourist staying period rose up to 16 days.the tourism sector has created 783,638 jobs for citizens in the last four years of the first GTP. Standardization of 400 star ranked Hotels has begun in the nation to increase the service quality delivered for the foreign visitors adding that International accredited standardization activities so far conducted on 50 hotels in Addis Ababa city. 


\section{Project Design and Methodology}

Relevant and necessary data was needed for this article to reach at final conclusion and to answer the challenge and prospect of Ethiopian tourism policy. Therefore it employed a qualitative approach to collect the necessary and relevant data.The study was also needed to conduct the necessary and reliable information by reviewing the available documents and needed to make a link or connection between different variables contributing to the challenge of tourism sector in Ethiopia.inaddition to this the researcher used field observation to asses the tourism industry in Ethiopia

\section{Result and discussion}

\section{Definition and Reality about Ethiopian tourism}

Tourism holistic definition that embraces both the factual and theoretical perspectives of tourism is desirable (Gilbert,1990). Jafari (1977) goes some way to achieving this by epistemologically defining tourism as ;The study of man away from his usual habitat, of the industry which responds to his needs, and of the impacts that both he and the industry have on the host's socio cultural, economic and physical environments. Nevertheless, tourism is primarily a social activity. If people had neither the ability nor the desire to travel from one place to another, tourism would not exist.

Thus, tourism is an activity which involves individuals who travel within their own countries or internationally, and who interact with other people and places, people who are influenced and motivated by the norms and transformations in their own society and who carry with them their own 'cultural baggage' of experience, expectations, perceptions and standards. It is, in short, a social phenomenon which involves the movement of people to various destinations and their (temporary) stay there or across the world.

As a land of multiple tourist attractions and a visitor friendly people which is conscious of its historical heritage, Ethiopia is truly a country of great tourism potential. It was this recognition of a great potential that encouraged Ethiopia in the 1960's to start a tourism industry. After an initial period of rapid growth, the industry underwent a fast decline and virtual stagnation for many years due to the revolution that brought the military to power in 1974, the consequent turmoil, and recurrent drought and famines.

During the last years, however, tourism has once again emerged as a growth industry taking advantage of the current peace and stability in the country and the liberalized economic policy of the new government. Ethiopia can now look forward to increasing its share of the world's tourism market which is registering a faster world-wide growth than most other industries.

Not all of Ethiopia's attractions are very widely known, but some are quite famous. Indeed, nine (9) national attractions (including, konso) have been recognized by UNESCO as world heritage: Axum's obelisks, Gondar's castles, the island monasteries on Lake Tana, Hadar (where Lucy was discovered), Tia's carved standing stones, the walls of Harar, the Semien National Park,and konso tradition and culture .Therefore the need for tourism policy now and then is un questionable.

Ethiopia's nearly ideal location on the African continent and its relative proximity to the Middle East and Europe can add to the comparative advantage which its numerous and varied attractions bestow on it. Though situated not far from the equator, much of the Ethiopian land has a climate tempered by high altitude. Ethiopia's tourism slogan "Thirteen Months of Sunshine" partly arises from the idyllic year-round, spring-like climate of most regions of the country. The first Ethiopian development plan was historically prepared in 1966. Then after the tourism industry was became as one sources of economic development until 1966. Through different years the sector show improvement in $12 \%$ within a year in average .During the Dreg regime tourism faced challenges like, war, drought and famine, ideological difference with western countries which are source of tourist and lack of concrete tourism policy which gives opportunity and guarantee for tourist sites was some of the challenges.

The Ethiopian Ministry of Culture and Tourism is responsible for developing and promoting the country's tourist products both locally and internationally by putting on ground the policy and strategy . It works closely together with different international and national stakeholders, the latter including Ethiopian Airlines, the Ethiopian Tour Operators Association (ETOA), and the Tourist Standard Hoteliers

According to ministry of culture and tourism, Ethiopia has a big size of population with diversified cultures that makes it an ideal tourist destination. So the country should also focus on inward looking programmes in terms of developing, promoting and expanding local tourism. The Ministry in its duties and powers is playing a decisive role for a concerted and multipurpose effort to be undertaken by the people and stakeholders in the development of tourism and culture.

Since the tourism industry is now globally lucrative, and one of the largest baseness in the world economy, preparation of various regulations, directives in order to study, preserve, control, register and conduct inventory of tangible and intangible cultural heritages apart from quality control and classification of standards in tourism area are some of the major areas that the Ministry focused in the 5-year strategic plans so that Ethiopia could be able to benefit the most out of the sector. 
The need for tourism policy

Since Ethiopia endowed with enormous manmade and natural tourist attraction area, having uniform tourism policy is unquestionable. Seventeen years of neglect "After the overthrow of the imperial government in the 1960 s and the coming to power of the socialist government in 1970, our country had a military government whose relations with tourist generating countries in Europe and America were bad", she explained. "For seventeen years, tourism was sorely neglected in our country By considering its socio-political, economic and cultural advantage, the current government launched tourism development policy in 2009. Ethiopia whose share of tourist flow to the East African Region of seventeen countrieswas at less than one percent in 2009 launched its first tourism development policy to reverse the situation.

The arrival of a new government in 1991 brought the first change, with greater emphasis on a freemarket economy, improving infrastructure and the construction of new roads, highways and airports. "Our present government considers tourism to be an industry with great potential for our country", says Dalacho, ministry of culture and tourism. "That's why the ministry of culture and tourism was formed to replace the tourism commission." As head of this ministry, recently finished drafting a new tourism policy for the government. Its main focal points include the following:

- Develop existing and new destinations with Ethiopia;

- Diversify the sector ;

- Improve infrastructure and tourism facilities;

- Create an enabling environment for private investors;

- Develop new and broader educational programmes for the sector so as to create a larger and more qualified labor force.

The government also aims to establish 'Tourism development Fund' with the key aim of mobilizing resources and capabilities of actors in the implementation of the policy. The establishment and application of the fund will be determined by a study and supported by law, according to the Policy launched at the Sheraton Addis in August 30, 2019. The new tourism policy of Ethiopia among other, aims to integrate/connect the development of the country's tourism with agricultural, industrial, foreign policies and strategies of the country.

\section{Ethiopian tourism policy and strategy}

\subsection{Vision}

To develop tourism in a responsible and sustainable way, enabling it to play a leading role in the economic development process of the country by executing its activities on a community based principle.

\subsection{Principles}

* Respecting diversity- Diversity of historical, cultural and natural wealth are the beauty and distinctive Features of Ethiopia; therefore, each of these has to be known, respected, and developed equally as tourism attractions.

* Ensuring participation and community benefits- Communities have to play a major in developing of the tourism industry, with each member participating and benefitting in the development process.

* Create a transparent and accountable work process- The process of tourism development requires the participation of many actors or stakeholders. Therefore, a good governance procedure shall be prepared in order that all stakeholders abide by professional tourism ethics.

* Create a sense of cooperation and coordination- Initiating continuous and good networking by creating strong cooperation communication and close relation between Regional, National and international bodies working in the tourism sector.

* Enhancing implementation capacity of the sector- To ensure the comparative advantage of the country in tourism development, by strengthening the implementation capacity of all parties in the sector to provide high quality tourism services

\subsection{Objectives}

* To consolidate the country's comparative advantage and enable the industry to compete in international tourist markets.

* To develop a tourism industry that can play a major role in generating and retaining international exchange

* To create increased employment opportunities for communities around the sites of attractions and distribute tourism income to improve living standards of the people.

* To build a tourism industry that can improve the image of the country and advance the growth of the sector in a sustainable manner.

* Promoting the country's tourist attractions and encourage expansion of local tourism

* Making the sector competitive in the world and Africa in its best destination for tourists and source of income for host country in direct and indirect economic benefit will be ensured.

* Bringing both culture and tourism to development so that the industry would contribute to the poverty 
reduction strategic plan and the Millennium Development Goals.

\section{Main issues of the Ethiopian tourism policy and strategies}

- To lead the country's tourism industry in a broad-based developmental direction

Though the strategy will give emphasis for:

- Creating strong relationships with other development strategies and policies to integrate directions .Here especially interlinking and connecting the tourism policy with agricultural and rural policy and strategy which helps to expand tourism attractions like eco-tourism in rural and agricultural areas. This coordination or chain of the rural to urban tourism used the sector direct beneficiary from on growing rural tourism development and give/provide input and artistic product for the urban tourism development as value chain. Indeed the policy strategy focus on :

- Development of the tourism environment

- Ensuring participation

- Increasing visitor volume

- $\quad$ Strengthening linkages in a cross-sectoral approach to poverty reduction

- Sequential development to avoid conflicts associated with mass tourism elsewhere

- To Develop new attractions and improving existing ones considering type, quality and quantity; possible strategy is:

- $\quad$ Developing high quality destinations and productions such as handicrafts

- Increasing flows of tourists in areas of the counties that are not in the current circuits

- $\quad$ Linking tour circuits to create a strong tourism package

- $\quad$ To develop crucial infrastructure and service delivery institutions

- $\quad$ Capacity building of federal and regional implementing structures

- Development of land and sea transport infrastructure, telephone and internet facilities and energy supply networks

- To make Ethiopia a competitive destination in the world tourism market

- Creation of an effective tourism promotion strategy

- Market analysis

- $\quad$ Building partnerships with domestic and international tour operators

- To coordinate the efforts of stakeholders

- Formation and consolidation of trade organizations

- Establishment of new fora:

- Tourism Management Council formed by officials from federal and regional tourism offices

- Government Tourism Common Forums formed from the relevant federal and regional executive bodies with NGOs, institutions and private sector stakeholders with interests in tourism

- $\quad$ To increase the current low capacity of the tourism industry

- Increase the capacity of major industry players with the introduction of professional standards for service providers

- Establishment of tourism training and education centres to address shortcomings in human resources development

- Improve the capacity state tourism institutions and systems in research, information dissemination and data collection and the creation and periodic publication of tourism satellite accounts.

The main thrust of this policy looks encouraging. Particularly important is the recognition that, in addition to providing a source of international exchange, the tourist sector can have a significant development impact through linkages with local communities. Also Government has clearly recognized the need to improve the competitiveness of the tourist sector and that improving the quality of tourism services is key to enabling Ethiopian tourism to compete in international markets and attract more tourists. Welcome also is the fact that Government clearly recognize their role in providing an enabling environment: through training of the workforce; provision of more accurate information; coordinating stakeholders including working with tour operators.In short, my view suggests that the thrust of this draft policy and implemented policy correctly addresses the key issues facing the tourist sector. As such, the tourism policy should be completed, ratified and implemented again correctly to strength more .

\section{The advantages of tourism in delivering pro-poor growth}

The negative impacts associated with tourism, such as reduced access to resources and negative social and cultural impacts sometimes threaten to overshadow the benefits that a vibrant tourism industry can generate. 
However if the policy implemented properly it will have the following benefits:

$\checkmark$ Tourism is generally labour-intensive - although less than agriculture - and therefore can impact on a large number of lives through the labour market;

$\checkmark$ Tourism has considerable potential linkage, especially with agriculture and fisheries, which can minimize the 'leakage' effect. Due to the high income elasticity of demand for international tourism, it can offer a relatively rapidly growing market;

$\checkmark \quad$ Tourism provides opportunities for off-farm diversification, particularly in areas that do not attract other types of development options;

$\checkmark \quad$ Tourism can provide poor countries with significant export opportunities where few other options are viable;

$\checkmark \quad$ It may create initial demand for a good or service that can itself develop into a growth sector;

$\checkmark$ Tourism products can generate demand for assets such as natural resources and culture, to which the poor often have access;

$\checkmark$ Tourism delivers consumers to the product rather than the other way around; and

$\checkmark \quad$ Infrastructure associated with tourism development can provide essential services for local communities. Indeed, throughout the world, the most compelling reason for pursuing tourism as a development strategy is its alleged positive contribution to the local or national economy. Internationally and localy, tourism represents an important source of foreign exchange earnings; indeed, it has been suggested that the potential contribution to the national balance of payments is the principal reason why governments support tourism development. For many developing countries, tourism has become one of the principal sources of foreign exchange earnings whilst even in developed countries the earnings from international tourism may make a significant contribution to the balance of payments in general, and the travel account in particular. It is also one of the reasons why tourism is frequently turned to as a new or replacement activity in areas where traditional industries have fallen into decline. The economic benefits (and costs) of tourism are discussed at length in the literature, as are the environmental and socio-cultural consequences of tourism. When we see Ethiopia various tourism sectors such as hotel, tour sites, natural and manmade caves, monuments ,historical religious places etc are become tourist destination areas. This is because of the promotion made by ministry of culture and tourism after the policy preparation and other organs, and by the improvement of facilities in tourist attraction areas. Gradually Many of these are considered in the context of development. The main point here, however, is that the widely cited benefits and costs of tourism, whether economic, environmental or socio cultural, are just that. They are the measurable or visible consequences of developing tourism in any particular destination and, in a somewhat simplistic sense, tourism is considered to be 'successful' as long as the benefits accruing from its development are not outweighed by the costs or negative consequences. For many developing countries, with a limited industrial sector, few natural resources and a dependence on international aid, tourism may represent the only realistic means of earning much needed foreign exchange, creating employment and attracting overseas investment.

Tourism in most sub-Saharan African countries is hardly an industry since the tourism infrastructure is weak, tourism organization is poor, and net revenue is meager. But now gradually Ethiopian is forwarding its base currently on tourism sector. Almost all tourist arrivals consist of African nationals' resident abroad returning to visit friends and relatives, business visitors, and those visiting expatriate residents. The primary vacation or leisure tourism sector is undeveloped (Teye, 1991, p. 288)

\section{Ethiopia's Historical \& Natural Tourist Attractions}

Currently, travel and tourism account for more than \$3 trillion in spending annually and 7.6 percent of the world's total employment. The United Nations World Tourism Organization further forecasts that international travel will double by 2020. Since a couple of decade, ecotourism has become a newer paradigm to tourism because in addition to offering economic and business opportunities for local communities, it strongly advocates reducing the environmental impact of travel, conserving natural resources, preserving cultural heritage, empowering and meeting the welfare of local people, and creating value for the travelers. It adds value to environments, communities, entrepreneurs and tourists within ethical objectives

The natural beauty of Ethiopia amazes the first-time visitor. Ethiopia is a land of rugged mountains ( some 25 are over 4000 meters high) broad savannah, lakes and rivers. The unique Rift valley is a remarkable region of volcanic Lakes, with their famous collections of birdlife, great escarpments and stunning vistas. Tisisat, the blue Nile falls, must rank as one of the greatest natural spectacles in Africa today. With 14 major wild life reserves, Ethiopia provides a microcosm of the entire subsaharan ecosystem. Bird life abounds, and indigenous animals from the rare walia ibex to the shy wild ass, roam free just as nature intended. Ethiopia, after the rains, is a land decked with flowers and with many more native plants than most countries in Africa.

The natural side of Ethiopia is an invaluable asset for its tourism industry, and inextricable from its cultural and historic features. Sustainable tourism, while preserving Ethiopia's natural environment, also serves to preserve the nation's rich cultural and environmental heritage. Ethiopia is endowed with a wide range of 
tourist attractions. Ecotourism potentials include paleo-anthropological sites-the famous finding of a hominid, Lucy; historic architectures such as the stelae and temples in Axum and Yeha; the monolithic rock-hewn church of Laliibela; the Castle of Fasilades in Gondar; the island monasteries of Lake Tana; the Camelot of Harar; the holiest mosques of Ahmed Negash in Tigrai, the Sof Omar in lowland Bale; the scenic beauty of the mountains of the Semyen, Wag and Lasta, and Bali; the Rift Valley lake; the Omo valley; and the fauna and flora that flourish in the natural terrains of the country. In addition, the myriad peoples of Ethiopia are very proud to deliver to tourists the original version of their subcultures including social organizations, artifacts, music, languages, religions, etc.

Ethiopian topography is endowed with gorgeous scenes of lofty peaks and enumerable species of wild life and birds. The country has a remarkably rich heritage and spectacular environment worth visiting by tourists interested in gaining knowledge of its history, culture, diversity of landscape, unique indigenous plants, birds, and mammals, and a great variety of interesting locations. Sight Seeing, Fishing, Bird watching, Safari Tours, Camping, climbing, Trekking, Hiking \& Walking, Water Sports, Caving etc could be mentioned as some of the interesting opportunities to invest on Ethiopian Ecotourism.

\section{Type of Tourism offered by Ethiopia}

Ethiopia's wealth of varied attractions gives it a great potential for cultural and educational tourism, photo safaris, hunting safaris, bird watching, water sports including river rafting, desert trekking, mountain camping and other forms of eco-tourism. Health tourism, on account of the cool climate of most regions of the country and the numerous hot springs in many volcanic areas, is an additional type of tourism with great potential.

Conference tourism, long aided by the presence of a number of international organizations in Addis Ababa including the headquarters of the Organization for African Unity and the Economic Commission for Africa (ECA), is poised to gain greater significance as a consequence of the newly built ultra-modern facilities at the ECA and the Sheraton Addis.

\section{Challenges of Ethiopian tourism}

Observably in most developed countries, the smokeless industry has the lion's share in the overall economic growth and development of a country. The tourism sector has now become a major source of income for various stakeholders engaged in the sector. In this regard, despite Ethiopia's endowment with various natural and man made heritages, it had not benefited much from the sector for years due to various factors. Currently, Ethiopia's tourism sector is booming in bike with its fast economic growth. It is also basking under stable peace and security as compared with other African countries. And that is why Ethiopia enjoyed the limelight as this year's ' Top Destination In The World For Tourists' by the European Council on Tourism and Trade (ECTT) because of excellent preservation of humanity landmarks. However, in the eyes of actors in the service sector and lessons got during the course of the last five years, this sector has its own prospects and challenges.

Under the coverage of community benefits, the sector suffer from unreasonable interference in most tourist destination areas by the local hotels, tour guides and the like. As compared to other African countries, travelling to tourist destinations proves a very costly adventure discouraging tourists from coming to Ethiopia.In some places, local residents want to sponge on tourists. Hence, the government, especially the Ministry of Culture and Tourism, should seriously take the responsibility of creating awareness among the community.Moreover, the number of graduates is increasing both from public and private institutions, there is still a shortage of skilled and capable human power. Thus, the Ministry needs to offer ultra-modern training to professionals and practical policy

\section{Summary}

A Tourism Development Policy has been implemented a years ago with a view to helpful in harnessing the untapped tourism potentials in the country. The tourism policy, harmonized in to other policies and strategies of Ethiopia's economy, has helped to improve the performance of travel and tourism sector. National air carrier for major network expansion, Conference tourism due to the presence of many international organizations such as AU and UNECA, a Rise in domestic and foreign private investment in hotels and a rise in development of travel and tourism due to growing international demand and the country's effort aimed at providing better ecotourism has also contributed positively to the expansion of ecotourism in the country. Partners' support also had its immense contribution.

Currently the Government is redesigning rigorously the tourism industry with a view to make it environmentally conscious, and go beyond the unfortunate goal of conventional tourism which was focusing on mere financial benefits but little or no regard for environmental degradation of tourist sites.

A new tourism and culture development policy is under discussion by all stakeholders and will shortly implemented. The newly amended policy understands that global tourism grows at the average annual rate of $4.3 \%$, the tourist industry in Ethiopia still accounts for less than 2 percent of Gross Domestic Product when 
compared to $6 \%, 14 \%$ and 5\% of GDP for Egypt, Kenya and of South Africa respectively. Cognizant of this, the government is looking for wider ways to double tourism earnings during 2010-2015 and see about one million foreign arrivals by 2020. In order to realize this goal, it intends to intensify its campaigns abroad of introducing the country as a top business and leisure destination. It also plans to introduce the country's ecotourism opportunities to new tourism markets such as India, China, Russia and Brazil. Its objective is to create social and economic benefits through ecotourism and to foster the conservation of natural resources of the areas. Participatory local initiatives, in collaboration with partners, will also be encouraged in a more organized way with a view to develop and introduce a consolidated approach for Eco-tourism that can be replicated in other areas and that enhances the sustainable utilization of the natural resources. The government is aware of current trends that, to attract tourists, the ecotourism industry must be designed to incorporate and implement responsible, ethical, forward-looking, and far-reaching environmental oversight. It is working to balance the economic, social and environmental management pillars of sustainable development.

Tourism has increasingly become a favoured development tool in many developing countries for poverty alleviation. For instance in eastern Africa tourism has scored tremendous improvement with the presence of stability in the area like in Kenya, Ethiopia Uganda etc.but still problems exist in Somalia. With the relative ease of entry into the tourism market and its purported ability to generate foreign exchange and create employment, it is no wonder that it is being pursued. However, like any development option or avenue of economic endeavor, it comes with a cost. This, then, is at the heart of the tourism development dilemma. Tourism represents an attractive, and perhaps the only, means of stimulating economic and social development for some developing nations.

However, frequently that development either fails to materialize, benefits only the local élite or multinational corporations, or is achieved with a very high social, environmental or economic cost. In the developing world, tourism is usually implemented through a top-down planning approach, and decision making is 'predominately based on the interventions of government agencies and large tourism firms, resulting in the dominance of external, often foreign capital and the marginalisation of local people' (Liu and Wall 2006). Developing countries opting into the tourism industry will encounter both the positive and negative consequences of this globally competitive industry, and the challenge lies in accepting or managing the negative consequences in the hopes of obtaining the potential long-term benefits of tourism. The complexities of using tourism as a development tool and the dilemma that many countries face in coping with the uncertainty that tourism brings have been.

Generally the tourism development process intersects with the economic, political, environmental and social conditions in the destination and is also framed by the global political economy. Despite the fact that tourist arrivals in Ethiopia is at an increasing mode because of policy measures, the sector in general is underperforming compares to neighboring destinations. Various domestic and international challenges are attributed to the low performance of the sector. Though the tourism development policy was designed well, the proper implementation of it is easier said than done. Lack of resources, weak coordination of institutions and failure of various stakeholders in playing their role are among the major causes for poor implementation

\section{Reference}

Adams, W. and Hulme, D. (1992) Conservation and Communities: Changing Narratives, Policies and Practices in African Conservation. Manchester: IDPM.

Acott, T., La Trobe, H. and Howard, S. (1998). An evaluation of deep ecotourism and shallow ecotourism. Journal of Sustainable Tourism 6 (3), 238-53.s of Mind and Being (pp. 172 82)

Ashley, Page \& Meyer (2004) Tourism and the Poor: Analysing and Interpreting Tourism Statistics from a Poverty Perspective

Gilbert, D. (1990) Conceptual issues in the meaning of tourism. In C. Cooper (ed.) Progress in Tourism, Recreation and Hospitality Management (vol. 2) (pp. 4-27). London: Belhaven Press.

Gilbert, D. (1991) An examination of the consumer behaviour process related to tourism. In C. Cooper (ed.) Progress in Tourism, Recreation and Hospitality Management (vol. 3) (pp.78-105). London: Belhaven Press.

Jafari, J. (1977) Editors page. Annals of Tourism Research 5 (1), 8.

Jafari, J. (1987) Tourism models: The sociocultural aspects. Tourism Management 8 (2): 151-9.

Jafari, J. (1989) Sociocultural dimensions of tourism: An English language literature review.

Sen, A.N., 1999, Development as Freedom, New York: Alfred A. Knopf.

Sinclair, M.T., 1998, “Tourism and Economic Development: A Survey,” Journal of Development Studies, 34 (5): 1-51.

Tadesse Kidane-Mariam(2015) Ethiopia: Opportunities and Challenges of Tourism Development in the Addis Ababa-upper Rift Valley Corridor, Department of Geography, Edinboro University of Pennsylvania, Edinboro, USA 
Telfer .J David and Sharpley Rechard (2008). Turism and Development in the Developing World . Routledge , Newyork and London

Temesgen Kasahun(2014).The Tourism Industry in Ethiopia. Mekelle University,Ethiopia

World Bank .Ethiopia: Towards a Strategy for Pro-Poor Tourism Development Prepared for the Government of Ethiopia, Report No. 38420 -ET. June 30, 2006. 